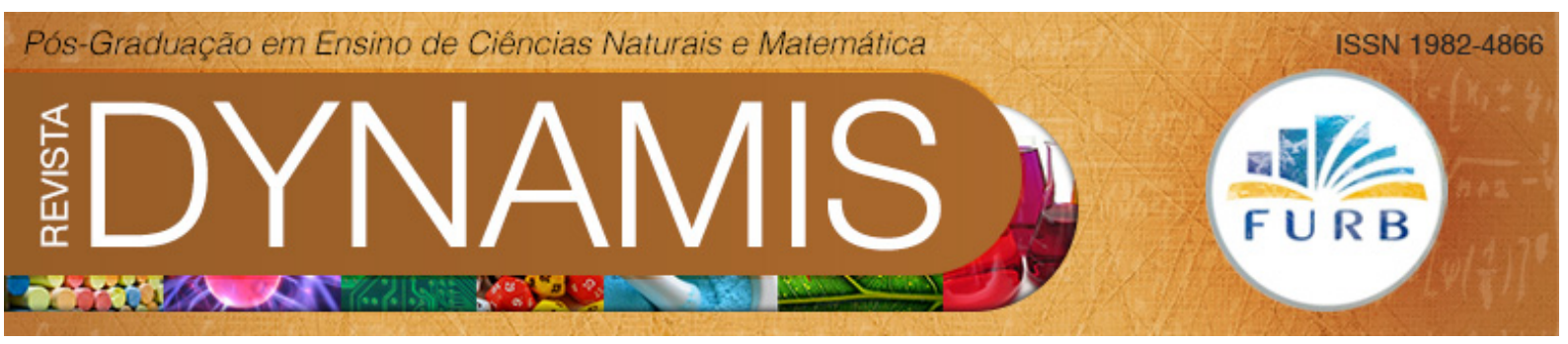

\title{
Sequência didática para 0 ensino de ciências nos anos iniciais: subsídios para iniciação à alfabetização científica
}

Sequence Teaching for Teaching Science in the Early Years: grants to initiation to scientific literacy

\section{Juliana Pinto Viecheneski}

UTFPR - Universidade Tecnológica Federal do Paraná

Especialista em Educação Infantil e Séries Iniciais e em Educação Científica e Tecnológica. Mestranda em Ensino de Ciência e Tecnologia, pela Universidade Tecnológica Federal do Paraná (UTFPR)

cajuzinhasp@gmail.com

\section{Marcia Regina Carletto}

UTFPR - Universidade Tecnológica Federal do Paraná

Doutora em Educação Científica e Tecnológica pela Universidade Federal de Santa Catarina.

marciahcarletto@uol.com.br 


\section{Resumo}

Este trabalho apresenta os resultados parciais de uma pesquisa em andamento sobre a importância do ensino de ciências e da iniciação à alfabetização científica nos anos iniciais do ensino fundamental. Objetiva apresentar as contribuições de uma sequência didática para a iniciação à alfabetização científica de alunos em processo de alfabetização da língua materna. A metodologia utilizada foi a pesquisa qualitativa, de natureza interpretativa, junto a crianças do $1^{\circ}$ ano do $1^{\circ}$ Ciclo do Ensino Fundamental de uma escola pública de Ponta Grossa - PR. Os principais resultados demonstram progressivo avanço dos alunos na participação, curiosidade, questionamento e interesse pela aprendizagem, indicando que uma sequência didática aplicada ao ensino de ciências, articulada ao processo de aquisição da língua materna torna as práticas de leitura e escrita contextualizadas e contribui para a concretização do ensino de ciências nos anos iniciais.

Palavras-chave: Alfabetização Científica; Ensino de Ciências; Anos Iniciais do Ensino Fundamental.

\section{Abstract}

This paper presents the partial results of a research work in progress on the importance of science education and science literacy for initiation into the first years of elementary school. Aims to present the contributions of a sequence for teaching scientific literacy of students in the literacy process of language. The methodology employed was a qualitative research, interpretative, with children of 1st year of the 1st Cycle Elementary School, a public school in the city of Ponta Grossa - PR. The main results showed a progressive advancement of students in the participation, curiosity, questions and interest in learning, indicating a sequence teaching applied for teaching science, articulated the process of acquiring language makes the reading practices and writing contextualized and contributes to the implementation of teaching science in the early years.

Keywords: Scientific Literacy; Science Teaching; First years of elementary school. 


\section{Introdução}

Em uma sociedade marcada pela forte presença da ciência e da tecnologia, espera-se que o ensino de ciências contribua, desde os primeiros anos de escolarização, para que o aluno adquira conhecimentos científicos e desenvolva capacidades de análise, interpretação, reflexão, comunicação, decisão, essenciais para o exercício da cidadania.

O ensino de ciências assume, assim, uma tarefa muito importante. Trata-se de possibilitar o acesso à cultura científica, de modo que cada sujeito tenha uma melhor compreensão do mundo e das transformações que nele ocorre e saiba utilizar os conceitos científicos aprendidos para enfrentar os desafios da vida e realizar escolhas responsáveis em seu cotidiano (BRASIL, 1997).

Entretanto, se por um lado é reconhecida a importância da democratização dos conhecimentos científicos desde o Ensino Fundamental, e o papel da escola na disseminação da cultura científica, por outro, as pesquisas em educação em ciências têm revelado uma situação preocupante no que se refere ao ensino dessa área, sobretudo nos anos iniciais do Ensino Fundamental.

Estudos apontam que muitos professores têm dificuldades em promover um ambiente desafiador, propício à investigação e à construção de conhecimentos em ciências (LIMA; MAUÉS, 2006; ROSA; PEREZ; DRUM, 2007; RAMOS; ROSA, 2008). A concretização de um ensino interdisciplinar e contextualizado ainda é um desafio para muitos docentes (BRANDI; GURGEL, 2002; ROSA; PEREZ; DRUM, 2007).

Outro aspecto evidenciado nas pesquisas e que interferem diretamente no processo de ensino e aprendizagem, são as concepções e crenças que professores dos anos iniciais possuem em relação ao trabalho com as ciências (LONGHINI, 2008; ROSA; PEREZ; DRUM, 2007). Há docentes que acreditam que os alunos dos anos iniciais não têm condições de compreender os conhecimentos científicos. Outros, apesar de reconhecerem a importância da ciência, não a contemplam em sala de aula porque se sentem inseguros para discutir e realizar um trabalho sistemático com as crianças (ROSA; PEREZ; DRUM, 2007).

Tal posicionamento se justifica pela formação precária dos professores e, em decorrência acabam assumindo uma visão equivocada a respeito do que significa ensinar ciências para crianças. Muitos enfatizam somente os conteúdos da área de Biologia, realizam poucas atividades experimentais e, muitas vezes, deixam as ciências em segundo plano, sobretudo no primeiro ciclo, em que as crianças estão em fase inicial de aprendizagem da leitura e escrita e do raciocínio matemático (ROSA; PEREZ; DRUM, 2007).

Todavia, diversos são os pesquisadores que defendem a importância do ensino de ciências desde as etapas iniciais da escolarização (CARVALHO et al., 1998; LORENZETTI; DELIZOICOV, 2001; BRANDI; GURGEL, 2002; LIMA; MAUÉS, 2006; HAMBURGER, 2007; ZANON; FREITAS, 2007; ROSA; PEREZ; DRUM, 2007; LONGHINI, 2008; RAMOS; ROSA, 2008; SASSERON; CARVALHO, 2008), dentre estes, pode-se citar Lorenzetti e Delizoicov (2001), quando afirmam que a alfabetização científica "pode e deve" ser realizada desde a entrada da criança no espaço escolar, mesmo antes da aquisição da leitura e escrita. Segundo os autores, a alfabetização científica pode auxiliar na apropriação do código escrito.

Diante do exposto, fica evidente a necessidade de transformação nas aulas dos anos iniciais. Além do despreparo dos professores, há a falta de compreensão acerca do processo e importância da alfabetização científica, bem como de metodologias adequadas e formação contínua em serviço que possibilitem sanar essas lacunas. Frente a essas questões, este 
trabalho apresenta os resultados parciais de uma pesquisa de mestrado profissional em andamento, cujo objetivo é apresentar as contribuições de um trabalho desenvolvido a partir de uma sequência didática para a alfabetização científica de alunos em processo de alfabetização da língua materna.

\section{Alfabetização Científica nos anos iniciais do Ensino Fundamental}

No âmbito do Ensino Fundamental, de acordo com Lorenzetti e Delizoicov (2001, p.89), a alfabetização científica nos anos iniciais, é entendida “[...] como o processo pelo qual a linguagem das Ciências Naturais adquire significados, constituindo-se um meio para o indivíduo ampliar o seu universo de conhecimento, a sua cultura, como cidadão inserido na sociedade."

Nesse contexto, o processo de alfabetização científica "pode e deve" ser desenvolvido desde a fase inicial de escolarização, mesmo antes da aquisição da leitura e escrita, contribuindo para a inserção do aluno na cultura científica, por meio de uma prática pedagógica interdisciplinar e contextualizada (LORENZETTI; DELIZOICOV, 2001).

Sobre essa questão, também, Brandi e Gurgel (2002) ressaltam que ao trabalhar os conteúdos de ciências, aliados à prática social dos alunos, é possível contribuir para a ampliação dos conhecimentos das crianças. Além disso, discutir e desvendar as relações existentes entre a sociedade, ciência e tecnologia, possibilita evitar a fragmentação dos conhecimentos e contribui para tecer uma nova perspectiva curricular para o ensino de ciências nos anos iniciais, em que o trabalho com as ciências, articulado ao processo de aquisição da língua materna, pode estimular atividades de leitura e escrita contextualizadas e repletas de significados para os alunos.

A alfabetização científica, na visão de Lorenzetti e Delizoicov (2001), é uma "atividade vitalícia" que pode ser sistematizada no ambiente escolar desde os primeiros anos de escolarização, lembrando que esse processo pode transcender os muros escolares quando for desenvolvido em contextos não formais de ensino.

Corroborando com essa ideia, Tenreiro-Vieira e Vieira (2011, p. 420) afirmam:

[...] reconhece-se a importância de, nas primeiras etapas de formação (primeiro e segundo ciclos do ensino básico português - crianças dos 6-12 anos), incorporar elementos básicos da cultura científica que impregna as sociedades atuais para que estejam presentes e se reflitam na construção dos primeiros esquemas de compreensão e atuação das crianças sobre o meio sócio-cultural; [...].

De acordo com os autores, os documentos de orientação curricular do ensino básico português assumem um posicionamento a favor da "literacia" (que neste trabalho denominamos alfabetização científica) com base na orientação CTS. Tal perspectiva também pode ser evidenciada na proposta educacional brasileira para o ensino de ciências. De acordo com os PCN's (BRASIL, 1997, p. 21-22), a apropriação de conceitos e procedimentos da área de ciências,

[...] pode contribuir para o questionamento do que se vê e ouve, para a ampliação das explicações acerca dos fenômenos da natureza, para a compreensão e valoração dos modos de intervir na natureza e de utilizar seus recursos, para a compreensão dos recursos tecnológicos que realizam essas mediações, para a reflexão sobre questões éticas implícitas nas relações entre Ciência, Sociedade e Tecnologia.

Os Parâmetros Curriculares Nacionais (BRASIL, 1997, p. 27) também destacam a importância de se incluir no trabalho pedagógico a história das ciências, como fonte de conhecimento que auxilia na construção de um olhar crítico acerca da ciência, tecnologia e suas interações com o meio social, compreendendo ciência e produção tecnológica como 6 
atividades não neutras, mas "[...] contextualizada nas relações entre as sociedades humanas e a natureza".

Nesse documento legal, a interdisciplinaridade e a contextualização são elementos muito enfatizados e associados à abordagem de temas. Os PCN's propõem que os conteúdos de ciências sejam desenvolvidos por meio da problematização de temáticas significativas que contemplem a ciência, a tecnologia, e suas interações com meio social.

Desse modo, pode-se afirmar que as orientações dos PCN's sugerem a formação de sujeitos cientificamente alfabetizados desde a fase inicial do Ensino Fundamental e apresentam aproximações e convergências com o enfoque CTS.

Entende-se que o ensino de ciências nos anos iniciais favorece não apenas a ampliação do repertório de conhecimentos das crianças, mas auxilia a desenvolverem habilidades e valores que lhes possibilitam continuar aprendendo, atingindo patamares mais elevados de cognição (LIMA; MAUÉS, 2006).

Além disso, o ensino de ciências pode contribuir para despertar nas crianças a curiosidade e o encantamento pela área científica, auxiliando para que o gosto pela ciência se mantenha e frutifique, mais tarde, em jovens interessados em seguir carreiras científicas (UNESCO, 2005), o que se constitui numa ação muito significativa, sobretudo, em um contexto em que poucos estudantes demonstram interesse profissional pelas áreas científicas.

Vale lembrar que o modo como a escola conduz o processo de ensino e aprendizagem, pode inibir o exercício da curiosidade do aluno, fazendo com que esta se perca à medida que progride para outras séries. Não raras vezes, contribui para que o gosto pelas ciências diminua, ou até mesmo se transforme em aversão (CARVALHO et al., 1998), o que provavelmente afetará as atitudes e escolhas futuras que os estudantes farão.

Segundo Carvalho et al. (1998, p.6), se a primeira vivência dos alunos com os conhecimentos de ciências for agradável,

[...] se fizer sentido para as crianças, elas gostarão de Ciências e a probabilidade de serem bons alunos nos anos posteriores será maior. Do contrário, se esse ensino exigir memorização de conceitos além da adequada a essa faixa etária e for descompromissado com a realidade do aluno, será muito difícil eliminar a aversão que eles terão pelas Ciências.

Desse modo, destaca-se a importância e a responsabilidade do professor que atua nos anos iniciais. Está em suas mãos a possibilidade de ajudar a criança a desvendar o mundo físico e social, bem como a tarefa de instigar a curiosidade e o encantamento pela área científica.

Assim, o ensino de ciências pode contribuir para, desde cedo, despertar a apreciação e o gosto pela ciência, mas também e, principalmente, contribuir para a formação da cidadania, de modo que as pessoas desenvolvam atitudes, valores sociais e capacidade para compreender, julgar e participar de processos decisórios que envolvam questões científicotecnológicas (AULER; DELIZOICOV, 2001; UNESCO, 2005; MARTINS; PAIXÃO, 2011).

Vale destacar ainda que o objetivo da escola, ao lado da promoção do conhecimento, "[...] precisa ser direcionado para sua apropriação crítica pelos alunos, de modo que efetivamente se incorpore no universo das representações sociais e se constitua como cultura" (DELIZOICOV et al., 2009, p. 34).

Corroborando essa ideia, Souza et al. (2007, p.2), discutem a necessidade das pessoas perceberem a ciência como parte de sua cultura. Indicam que embora as tecnologias façam parte do cotidiano da população, isso não significa que a sua compreensão já esteja 
incorporada na cultura. As pessoas se posicionam perante assuntos como futebol, religião, entre outros, no entanto, quando as questões se reportam à ciência e tecnologia, "[...] não se envergonham em dizer o quanto desconhecem o assunto".

A atuação docente precisa, então, levar os alunos desde cedo a compreenderem a ciência e a tecnologia como um empreendimento humano, como parte integrante da cultura, assim como é a música, o teatro, a literatura, e que, portanto, todos devem ter o direito de conhecer, julgar e participar nas decisões (DELIZOICOV et al., 2009).

É nesse sentido que Lorenzetti e Delizoicov (2001) propõem um ensino de ciências que não esteja voltado tão somente para a formação de futuros cientistas, mas uma proposta capaz de fornecer conhecimentos para que os alunos possam compreender, discutir questões de âmbito científico-tecnológico e sejam capazes de utilizar os conhecimentos adquiridos para entender e agir em seu mundo.

Sasseron e Carvalho (2008) também partem do pressuposto de que é necessário promover a alfabetização científica desde os anos iniciais de escolarização. As autoras realizaram um estudo, no qual inseriram os alunos das séries iniciais na discussão de temas CTSA (Ciência-Tecnologia-Sociedade e Meio Ambiente). Aplicaram uma sequência didática para o ensino de ciências junto às crianças de uma terceira série do ensino fundamental, com objetivo de iniciar o processo de alfabetização científica com a turma selecionada.

Os resultados apresentados por Sasseron e Carvalho (2008) destacam a importância da participação ativa dos alunos na construção do conhecimento e a necessidade da discussão de problemas e desafios que se fazem presentes na realidade atual. Nessa perspectiva defendem as propostas de atividades investigativas, nas quais se contemplem as interações entre ciência, tecnologia, sociedade e meio ambiente, como meio de inserir os alunos na cultura científica, propiciando um ensino contextualizado e interdisciplinar.

Segundo as autoras, é importante que o professor traga à pauta da sala de aula não só questionamentos e estudos sobre os avanços científicos e tecnológicos, mas também, sobre os impactos e consequências que esses podem trazer para a população e o planeta como um todo. Enfatizam que é preciso, desde os anos iniciais, despertar para o pensamento crítico, para o questionamento, instrumentalizando os alunos para que saibam usar os conhecimentos adquiridos na escola para fazer escolhas conscientes, com vistas a uma melhor qualidade de vida.

Cabe ressaltar que colocar em prática tal perspectiva de trabalho, a favor da alfabetização científica dos alunos, exige assumir uma postura transformadora no espaço escolar (LORENZETTI; DELIZOICOV, 2001).

\section{Metodologia}

Delineou-se como norteadora desse trabalho a seguinte indagação: Que estratégias de ensino e aprendizagem podem contribuir para a iniciação à alfabetização científica de alunos dos anos iniciais do Ensino Fundamental?

Optou-se como alternativa metodológica pelo desenvolvimento de uma pesquisa aplicada em uma turma do $1^{\circ}$ ano do $1^{\circ}$ Ciclo do Ensino Fundamental, pelo fato de as crianças se encontrarem em etapa inicial de aquisição da língua materna. Assim, o estudo foi desenvolvido em uma escola da rede pública do município de Ponta Grossa - PR, numa classe composta por 25 alunos, cuja faixa etária varia entre 5 e 6 anos.

Entende-se que a abordagem metodológica mais adequada para responder a problemática em questão, foi a abordagem qualitativa, de caráter interpretativo. Neste 
trabalho, partiu-se do pressuposto de que o processo de ensino e aprendizagem de ciências, a partir das orientações epistemológicas do enfoque CTS, contribui para a alfabetização científica dos alunos dos anos iniciais, como também, propicia às atividades de leitura e escrita maior contextualização e significado. Desse modo, foi aplicada uma sequência didática, a partir do tema "alimentação humana", por se entender que esse tema atende aos seguintes critérios:

a) É um tema que desperta interesse nos alunos e possui relevância para a vida atual e futura;

b) Possibilita o estabelecimento das inter-relações entre ciência, tecnologia e o contexto social, como forma de auxiliar os estudantes na compreensão do mundo contemporâneo;

c) Favorece a abordagem interdisciplinar e contextualizada dos conteúdos, partindo de situações-problema presentes no dia a dia, capazes de despertar nas crianças a curiosidade e a necessidade de construir coletivamente conhecimentos;

d) Favorece o desenvolvimento de capacidades e atitudes necessárias ao exercício da cidadania e ao convívio social, tais como: capacidade de análise, interpretação e reflexão, gosto pela participação, espírito investigador, capacidade de comunicar-se oralmente e por escrito, escuta, cooperação e respeito pelas diferentes ideias.

Os dados foram coletados por meio da aplicação de teste diagnóstico, observação, gravações em áudio, fotografias, registros escritos, ilustrações realizadas pelas crianças e pósteste. O trabalho pedagógico foi organizado em dez intervenções, com duração de duas a quatro horas/aula cada uma, que aconteceram ao longo de dois meses. As intervenções foram organizadas com base no seguinte esquema, proposto por Dolz, Noverraz \& Schneuwly (2004):

Figura 1 - Esquema da sequência didática

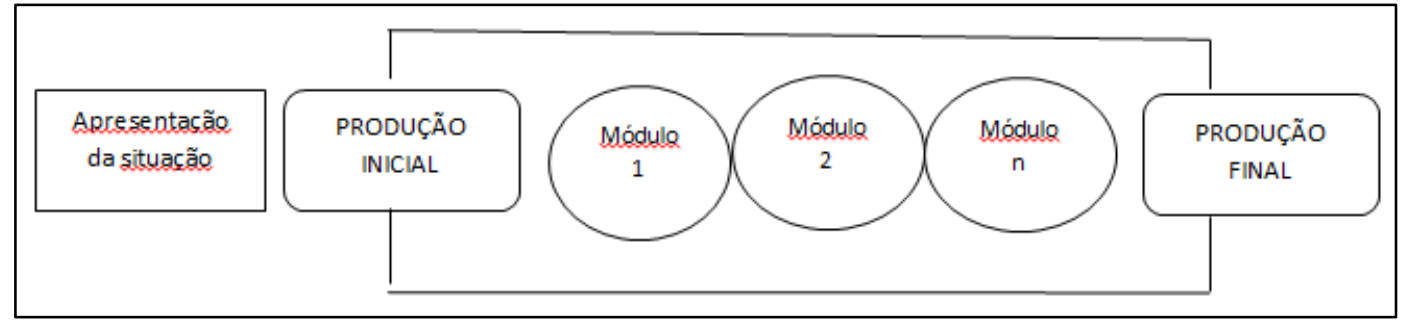

Fonte: Dolz, Noverraz e Schneuwly (2004, p.98)

No início do projeto foi aplicado um teste diagnóstico, com o objetivo de verificar os conhecimentos prévios das crianças e orientar o planejamento face à realidade e conhecimentos dos alunos e ao final das intervenções em sala de aula, houve a aplicação de um pós-teste, visando a possibilidade de estabelecer um parâmetro comparativo do processo de aprendizagem dos alunos, utilizando como referência o teste diagnóstico aplicado no início do projeto.

A sequência didática aplicada seguiu os passos relacionados abaixo:

1) Apresentação da situação - Nesta etapa o professor detalha a tarefa a ser realizada e delimita o estudo e as ações que serão desenvolvidas até a etapa da produção final. 
2) Produção inicial - Possibilita uma avaliação dos conhecimentos prévios dos alunos e o ajuste, quando necessário, das atividades previstas, considerando os conhecimentos que a classe já domina, suas potencialidades e dificuldades.

3) Módulos - Em cada módulo o professor trabalha os conteúdos e os "problemas" identificados na produção inicial, fornecendo aos alunos os instrumentos necessários para superação. Nesse trabalho foram desenvolvidos 8 módulos, conforme segue: Módulo 1 Alimentos: fonte de energia e matéria-prima; Módulo 2 - O que é se alimentar bem?; Módulo 3 - Suco natural, de pacote artificial ou refrigerante: qual o melhor para a gente?; Módulo 4 A tecnologia no cotidiano; Módulo 5 - A tecnologia e seu uso; Módulo 6 - Perigos ocultos; Módulo 7 - Brincando de vendedor e consumidor e Módulo 8 - Compondo uma cartilha.

4) Produção final - Etapa em que o aluno tem a oportunidade de colocar em prática as aprendizagens adquiridas nos módulos e, com o professor, avaliar os avanços conquistados. Esse momento possibilita observar os conhecimentos aprendidos, bem como fornece subsídios ao planejamento da continuidade do trabalho (DOLZ; NOVERRAZ; SCHNEUWLY, 2004).

Em função de alguns módulos ainda encontrarem-se em fase de análise, nesse artigo serão abordadas as atividades realizadas na produção inicial e nos módulos 1,2 e 3 . A fim de garantir o anonimato e a confidencialidade das informações, os alunos participantes do estudo foram identificados por letras do alfabeto, sem correspondência entre essas e as iniciais de seus nomes. A análise dos dados foi realizada paralelamente às intervenções em sala de aula, após leitura, releitura e confronto dos dados coletados.

\section{Resultados e discussão}

Após a apresentação da situação, que possibilitou aos alunos conhecerem a proposta de trabalho, foi realizada a aplicação do teste diagnóstico. Esse teste caracterizou-se como a produção inicial dos alunos e revelou os seus conhecimentos espontâneos acerca do tema "alimentação humana". Partindo-se, então, dos conhecimentos prévios das crianças, as atividades dos módulos da sequência didática foram desenvolvidas. Observou-se que no início do projeto, quando deparados com questões que solicitavam defesa ou justificativa de uma posição, ou ainda realização de escolha de alimentos e posterior justificativa, algumas crianças tendiam a não responder ou a repetir o que um colega falava e a grande maioria não era coerente nas suas tentativas. Porém, no decorrer das atividades, constatou-se um progressivo avanço dos alunos.

Para ilustrar, incluem-se abaixo, exemplos de respostas dos alunos a solicitações realizadas em uma atividade desenvolvida no teste diagnóstico. $\mathrm{Na}$ tarefa em questão, os alunos deveriam realizar uma escolha, entre vários alimentos, para que fizessem parte das suas refeições diárias e justificar oralmente ou por escrito quais motivos os levaram a escolher aqueles alimentos. 
Figura 2 - Atividade diagnóstico inicial, realizada pelo aluno E.

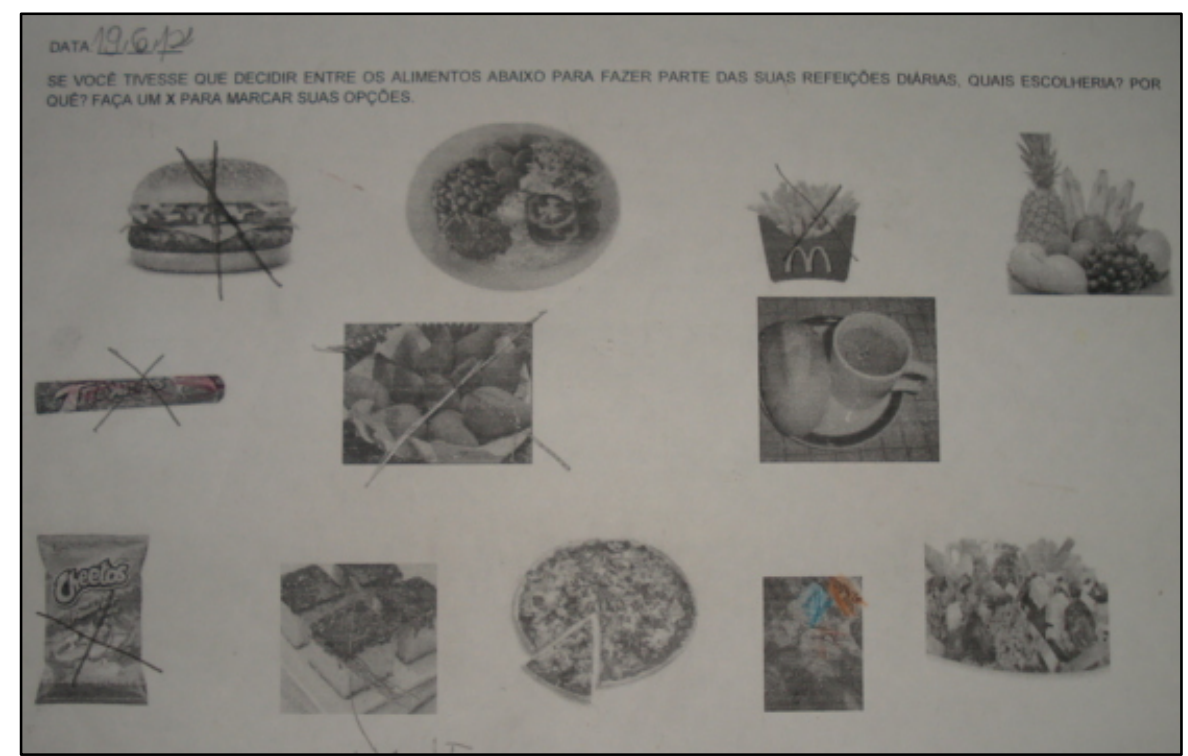

Fonte: Fotos da pesquisa

Ao questionar as razões que levaram o aluno E (5 anos), a realizar essa escolha de alimentos, o aluno afirmou: Faz bem para saúde. Observou-se que nessa atividade, a maioria das demais crianças indicou alimentos como: bolacha recheada, batata-frita, sanduíche, coxinha, chips e justificaram a escolha afirmando que a fizeram por que: $\dot{E}$ saudável $(D, 5$ anos )Para ficar forte ( $P$, 6 anos); Para crescer (C, 5 anos); Quero ficar grande (S, 5 anos).

Entretanto, progressivamente, as crianças foram avançando em seus conhecimentos. No decorrer do projeto, verificou-se que poucos alunos sentiam dificuldades em explicitar posicionamentos e fornecer justificativas claras e coerentes. Observou-se ainda que as crianças, para responderem aos questionamentos realizados pela professora, procuravam mobilizar os conhecimentos trabalhados.

O pequeno texto a seguir, produzido coletivamente pelos alunos, indica que de modo geral, as crianças reconheceram a importância de determinados alimentos para o ser humano e observa-se que as afirmações são seguidas de justificativas coerentes, que denotam a mobilização de conhecimentos construídos.

\section{A importância dos alimentos}

As frutas são importantes porque têm muita vitamina. Os legumes também. Nosso corpo precisa de muita água e suco.

Bolos e doces devemos comer pouco, porque têm muito açúcar.

Os exemplos a seguir mostram que as crianças conseguiram apontar corretamente os alimentos que precisam estar presentes nas suas refeições diárias e quais são os que precisam ingerir em menor frequência. Verificou-se ainda que cinco alunos elencaram não apenas os alimentos presentes na pirâmide construída em sala de aula, mas apresentaram também outros alimentos, indicando que houve a generalização do conhecimento. 
Figura 3 - Atividade de registro a partir da pirâmide alimentar

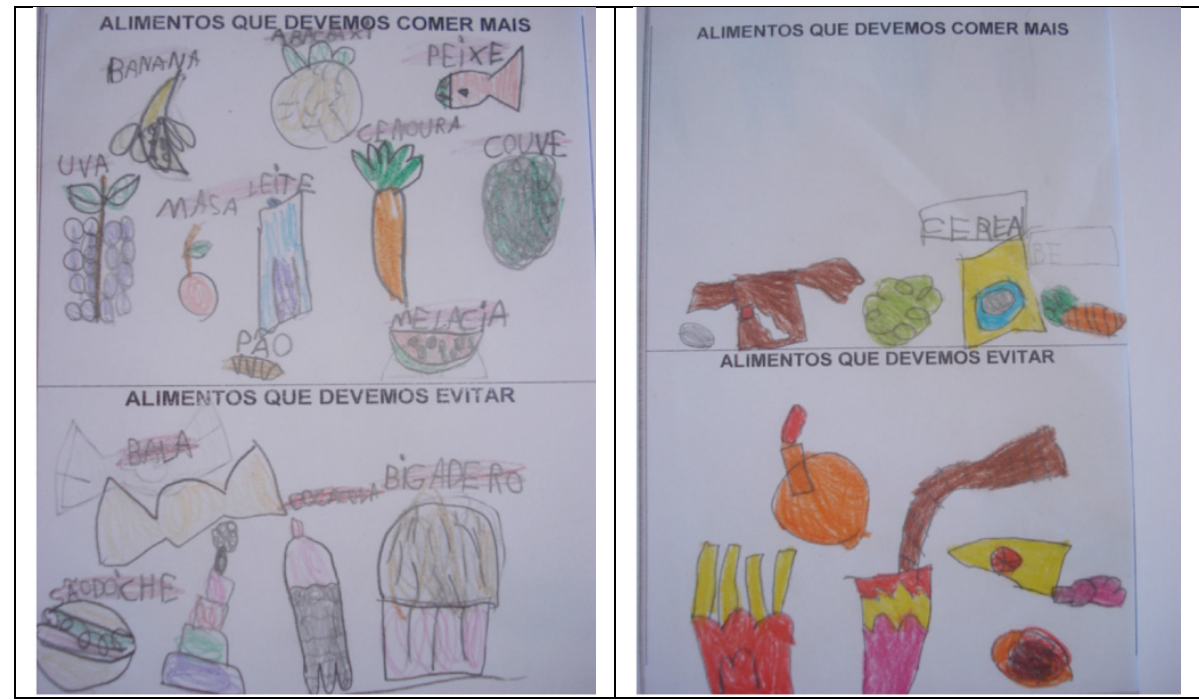

Fonte: fotos da pesquisa.

Em outra atividade, as respostas ilustradas indicam que os alunos assumiram uma posição, expressando justificativas que as sustentam. Ao responder a seguinte indagação - Se vocês tivessem que escolher entre suco de pacotinho artificial, refrigerante ou um suco natural, qual seria a opção mais adequada? Por quê? - Obtiveram-se respostas como: Suco natural, porque não pode tomar muito refrigerante porque tem muito açúcar (H, 5 anos); Suco natural, porque tem fruta e a fruta tem vitamina ( $N, 5$ anos); $O$ suco natural porque a gente sabe quanto vai de cada ingrediente ( $V, 5$ anos).

O mesmo pôde ser verificado nos exemplos abaixo, na atividade de registro realizada, em que os alunos escreveram: Saudável e muito bom ( $G, 6$ anos); Porque faz bem para saúde (B, 5 anos); É alimento que faz bem e gostoso ( $V, 5$ anos). Essa é uma atividade importante porque conduz o aluno a um pensar sobre as suas escolhas e ao compartilhar com a professora e os colegas, a criança é levada a reelaborar seus pensamentos para justificar um posicionamento, comunicando-o ao grupo.

Figura 4 - Atividade de registro

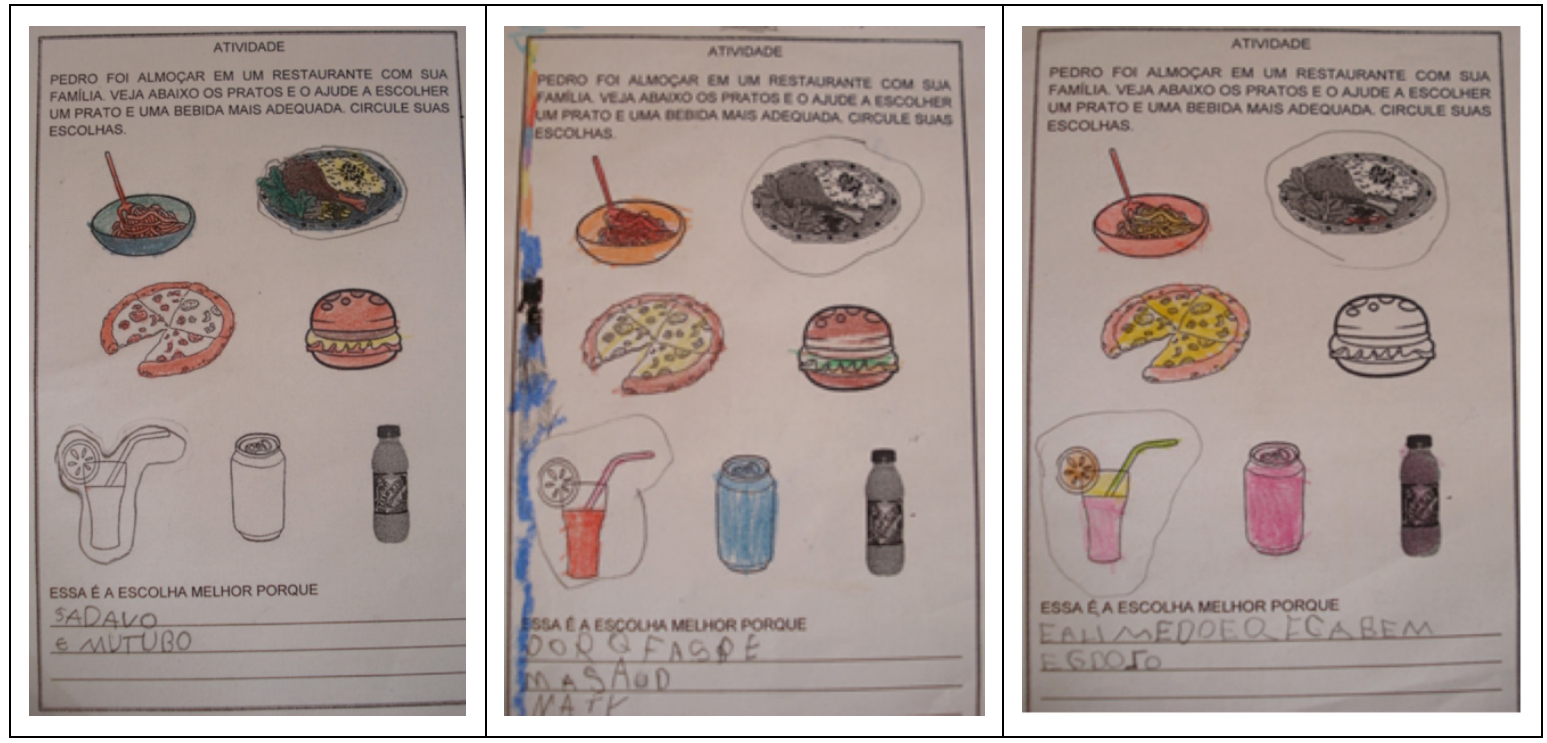

Fonte: Fotos da pesquisa 
Entende-se que discussões mais aprofundadas sobre o desenvolvimento científicotecnológico, no que se refere ao tema alimentação, envolvendo os fatores econômicos, políticos, sociais, assume complexidade e é abstrato às crianças do $1^{\circ}$ ano, que são o foco desse trabalho. Entretanto, defende-se que desde o início da escolarização, o aluno seja colocado frente a situações concretas que envolvam a ciência, a tecnologia e a sociedade, buscando tecer relações entre estas e o seu dia a dia, de modo que os alunos sejam iniciados num processo de reflexão e análise crítica do seu meio.

Assim, as discussões em sala de aula foram realizadas de maneira a não exigir uma ampliação e profundidade fora do alcance das crianças, mas que dentro das possibilidades de seu estágio cognitivo, pudessem propiciar um espaço de reflexão, análise, compartilhamento e confronto de ideias, por entender que essa tarefa não pode ser remetida apenas às séries escolares mais adiantadas.

Nesse contexto, as discussões envolveram assuntos como: propagandas e consumo, alimentos naturais e industrializados, o uso dos artefatos tecnológicos no cotidiano, a história de evolução de alguns artefatos tecnológicos, os perigos que se pode encontrar nos alimentos (perigo biológico, perigo químico, perigo físico) as fontes de microrganismos, condições de higiene e segurança alimentar. Pelo fato dos dados ainda encontrarem-se em análise e pelo limite de páginas imposto, tais discussões não serão abordadas neste artigo.

No que se refere às estratégias utilizadas no âmbito do desenvolvimento da sequência didática, observou-se que o uso da constante problematização, realizada por meio de questionamentos lançados aos alunos a partir do tema em estudo, foi estratégia que favoreceu a aprendizagem das crianças. $\mathrm{O}$ momento de problematização gera, além do espaço que propicia o pensar, o compartilhamento e o confronto de ideias, a aprendizagem de atitudes imprescindíveis ao exercício da cidadania, como respeito às regras combinadas em grupo, respeito pelas diferentes ideias, capacidade de se comunicar, de ouvir e esperar sua vez para se expressar. Vale lembrar que atitudes e valores se constroem desde cedo e nesse sentido, faz-se necessário que a escola proporcione momentos para que essa aprendizagem aconteça.

O uso sistemático de materiais veiculados pelos meios de comunicação, como as propagandas sobre consumo de refrigerantes, demonstrou contribuir para iniciar o aluno num processo de interpretação e análise crítica das ideias presentes nas mídias. $\mathrm{O}$ trabalho sistemático com vídeos que abordam a temática, também indicou ser uma estratégia produtiva, que prende a atenção das crianças e contribui para ampliação dos seus conhecimentos.

Outra estratégia que demonstrou auxiliar na iniciação dos alunos à alfabetização científica e ao mesmo tempo contribuiu para a aprendizagem da leitura e escrita, foi a realização de diversos momentos de leitura, individuais e coletivas, com o uso de diferentes tipos de textos relacionados ao tema estudado, como textos informativos, rótulos de produtos alimentícios, livros de literatura, receita e propagandas.

A questão que sempre fica é: como trabalhar uma temática da área de ciências, com práticas de leitura com alunos que ainda não sabem ler? Sobre essa questão, Goulart (2006, p. 96) ressalta que: "[...] É no contato com materiais escritos e com a mediação de um leitor mais experiente, que a criança vai buscando compreender o sentido do que está escrito [...]".

No âmbito escolar, o leitor mais experiente é o professor ou até mesmo um colega de classe, e é por meio de intervenções do professor e do contato com os textos que as crianças vão ampliando seus saberes e criando estratégias de leitura. Assim, é pelo intermédio de atividades que inserem os alunos em práticas sociais de leitura e escrita, que as crianças gradativamente vão se apropriando de tais conhecimentos (LEAL et al., 2006). Para tanto, 
faz-se necessário propiciar a vivência, o contato contínuo e sistematizado com materiais escritos de diversos gêneros textuais e sobre os mais variados assuntos.

No âmbito do desenvolvimento deste projeto, as práticas de leitura compartilhada, bem como as produções escritas individuais e coletivas realizadas, constituíram-se em estratégias que demonstraram bons resultados em sala de aula, tanto na construção de conhecimentos na área de ciências, como no processo de aprendizagem da língua materna, propiciando a esse processo maior contextualização e significado, pelo fato de propiciar práticas reais de leitura e produção de texto.

\section{Considerações Finais}

Este trabalho centrou-se em mostrar os resultados parciais de uma pesquisa de mestrado profissional em andamento, cujo objetivo é apresentar as contribuições de um trabalho desenvolvido a partir de uma sequência didática para a alfabetização científica de alunos em processo de alfabetização da língua materna.

Tal como lembram Lorenzetti e Delizoicov (2001) e Tenreiro-Veira e Vieira (2011), a alfabetização científica é um processo de construção que se prolonga por toda a vida. Contudo, é fundamental que seja desenvolvida desde os primeiros anos de escolarização, para que os pequenos cidadãos, desde cedo, já possam ir construindo valores e habilidades necessárias a um sujeito consciente, autônomo, capaz de julgar, tomar decisões e agir com vistas a uma melhor qualidade de vida.

Os resultados até aqui analisados apontam que a sequência didática, desenvolvida a partir do tema das ciências "alimentação humana" articulada ao processo de aquisição da língua materna, tornou as práticas de leitura e escrita mais contextualizadas e significativas e contribuiu para a ampliação dos conhecimentos das crianças, despertou-lhes a curiosidade e o interesse pelo tema científico trabalhado, percebido na forma espontânea e gradual como as trocas verbais e pequenas perguntas foram sendo feitas, na participação efetiva das atividades propostas e no entusiasmo em realizá-las.

Nesse sentido pode-se afirmar que o ensino de ciências nos anos iniciais, possui potencial para auxiliar na construção de valores e habilidades, quando a escola proporciona um espaço rico em interações dialógicas, reflexões, aprendizagem do questionamento, da capacidade de se comunicar, de ouvir e esperar sua vez para se expressar, do respeito pelas diferentes ideias, do respeito às regras combinadas em grupo, da responsabilidade e do senso crítico.

Verifica-se assim, que as atividades dos módulos da sequência didática, aqui apresentados, contribuíram para o avanço progressivo dos conhecimentos dos alunos, tanto em relação às questões subjacentes ao ensino de ciências e à iniciação da alfabetização científica, quanto em relação ao processo de alfabetização da língua materna, demonstrando que é possível, desde a fase inicial de escolarização, concretizar um trabalho interdisciplinar e contextualizado, centrado na formação para a cidadania.

Vale ressaltar que o desafio da implementação de uma prática dialógica e integrada, exige esforço coletivo. Nessa perspectiva, o apoio e a orientação pedagógica, aliados a uma formação profissional consistente e contínua, são fundamentais para potencializar a transformação necessária nas aulas de ciências dos anos iniciais. Conforme apontam Carvalho e Gil-Pérez (2006), é importante que em cada espaço educativo, o trabalho docente venha a se concretizar como tarefa coletiva de reflexão, ação, pesquisa e formação permanente.

\section{Referências}


Auler, D.; Delizoicov, D. (2001). Alfabetização científico-tecnológica para quê? Ensaio Pesquisa em Educação em Ciências, 3(1), 1-13.

Brandi, A. T. E.; Gurgel, C. M. A. (2002). A alfabetização científica e o processo de ler e escrever em séries iniciais: emergências de um estudo de investigação-ação. Ciência \& Educação, 8(1), 113-125.

Brasil. Secretaria de Educação Fundamental. (1997). Parâmetros curriculares nacionais: ciências naturais. Brasília: MEC/SEF.

Carvalho, A. M. P.; et al. (1998). Ciências no ensino fundamental: o conhecimento físico. São Paulo: Scipione.

Carvalho, A. M. P. de; Gil-Pérez, D. (2006). Formação de professores de ciências. (8a ed.) São Paulo: Cortez.

Delizoicov, D.; et al. (2009). Ensino de ciências: fundamentos e métodos. (3a ed.) São Paulo: Cortez.

Dolz, J.; Noverraz, M.; Schneuwly,B. (2004). Gêneros orais e escritas na escola. (pp. 95128). São Paulo: Mercado de Letras.

Fontana, R.; Cruz, N. (1997). Psicologia e trabalho pedagógico. São Paulo: Atual.

Goulart, C. (2006). Ensino fundamental de nove anos: orientações para a inclusão da criança de seis anos de idade (pp.87-98) Brasília: MEC/SEF.

Hamburger, E. W. (2007). Apontamentos sobre o ensino de ciências nas séries escolares iniciais. Estudos Avançados, 21(60), 93-104.

Leal, T. F.; Albuquerque, E. B. C. de. Morais, A. G. de. (2006). Ensino fundamental de nove anos: orientações para a inclusão da criança de seis anos de idade (pp.71-85) Brasília: $\mathrm{MEC} / \mathrm{SEF}$.

Lima, M. E. C. de C.; Maués, E. (2006). Uma releitura do papel da professora das séries iniciais no desenvolvimento e aprendizagem de ciências das crianças. Ensaio - Pesquisa em Educação em Ciências, 8(2), 161-175.

Longhini, M. D. (2008). O conhecimento do conteúdo científico e a formação do professor das séries iniciais do ensino fundamental. Investigações em Ensino de Ciências, 13(2), 241-253.

Lorenzetti, L.; Delizoicov, D. (2001). Alfabetização científica no contexto das séries inicias. Ensaio - Pesquisa em Educação em Ciências, 3(1), 1-17.

Martins, I. P.; Paixão, M. de F.(2011). CTS e educação cientifica: desafios, tendências e resultados de pesquisas (Cap. 5 pp.135-160). Brasília: Editora Universidade de Brasília.

Ramos, L. B. da C.; Rosa, P. R. da S. (2008). O ensino de ciências: fatores intrínsecos e extrínsecos que limitam a realização de atividades experimentais pelo professor dos anos iniciais do ensino fundamental. Investigações em Ensino de Ciências, 13(3), 299331. 
Rosa, C. W.; Perez, C. A. S.;Drum, C. (2007). Ensino de física nas séries iniciais: concepções da prática docente. Investigações em Ensino de Ciências, 12(3), 357-368.

Sasseron, L. H.; Carvalho, A. M. P. de. (2008). Almejando a alfabetização científica no ensino fundamental: a proposição e a procura de indicadores do processo. Investigações em Ensino de Ciências, 13(3),333-352.

Souza, C. A.; et al. (2007). Cultura científica-tecnológica na educação básica. Ensaio Pesquisa em Educação em Ciências, 9(1), 1-13.

Tenreiro-Vieira, C.; Vieira, R. M. (2011). CTS e educação cientifica: desafios, tendências e resultados de pesquisas (Cap. 14, pp. 417-438). Brasília: Editora Universidade de Brasília.

UNESCO Brasil. (2005). Ensino de Ciências: o futuro em risco. Recuperado em 01 junho, 2011, de http://unesdoc.unesco.org/images/0013/001399/139948por.pdf.

Zanon, D. A. V.; Freitas, D. (2007). A aula de ciências nas séries iniciais do ensino fundamental: ações que favorecem a sua aprendizagem. Ciências e Cognição, 10, 93103. 